\title{
The transverse impact responses of 3-D braided composite I-beam
}

\author{
Haili Zhou $^{\#, 1,2}$, Dongmei Hu ${ }^{\#, 1,3}$, Wei Zhang ${ }^{1}$, Bohong Gu ${ }^{1,2}$, Baozhong Sun ${ }^{1,2, *}$
}

\begin{abstract}
This paper reports the transverse impact responses of 3-D braided composite I-beam from experiment and finite element analysis (FEA). The transverse impact tests were conducted on a modified split Hopkinson pressure bar (SHPB). Three different impact gas pressures were set to research the effect of the impact velocity on the transverse impact behaviors of the I-beams. A microstructure geometric model was established to model the real structure of 3-D braided composite I-beam. The mechanical responses including load-time history, displacement-time history and energy absorption were obtained. Damage process and stress distribution were analyzed from the FEA result. From the result, the complex braided structure remarkably affected the stress state of different braiding yarns. Finally, the fracture morphologies obtained from FEA and experimental results showed a good agreement which validated the established model.
\end{abstract}

\section{Key words}

A. Textile composites; B. I- beam; C. Transverse impact tests; D. Finite element analysis (FEA); E. Braiding 


\section{Introduction}

3-D braided technique is superior in manufacturing the multidirectional near-net shape preform. 3-D braided composite has gained wide attention for its high impact resistance and damage tolerance, low delamination and structural integrity[1]. I-shape composite beam has high bending stiffness for the continuously oriented fibers in the braiding structure[2].

I-beam is a common structure used in engineering application. The mechanical behaviors of the composite I-beams have been investigated extensively [2-9]. Barbero et al[4] and Shin et al[6] presented numerical methods to predict the mechanics of thin-walled composite I beam. Szak et al[5] and Hai et al [7]studied the performance of hybrid FRP I-beam by four-point bending test. However, only a few of them were focused on 3-D braided composite I-beam. Hamada et al. [2] studied the crushing fracture behaviors of braided I-beams with different cut shape types. Yau et al[3] presented the mechanical response of 3-D braided composite I-beams under flexural and axial compressive loading.

The transverse impact behaviors of 3-D textile structure composite beams have been investigated in references [10-15]. Hao et al[10] and Zhang et al[11] researched the dynamic behaviors of 3-D orthogonal woven and biaxial spacer weft-knitted composite T-beam experimentally and established unit cell model for finite element analysis. Zhang et al [14]and Yan et al[15] studied the impact behaviors of 3-D rectangular braided composite beams. However, the transverse impact behaviors of 3-D braided composite I- beam have not been reported comprehensively so far.

This paper will investigate the transverse impact responses of 3-D braided composite I-beam from both experimental and finite element analysis approaches. The transverse impact tests were conducted on a modified split Hopkinson pressure bar. Load-time history, displacement-time history and energy absorption will be given. A microstructure model of 3-D braided composite I-beam was established for the finite element analysis (FEA). From the FEA results, the stress propagation and stress 
distribution in braiding yarns and matrix as well as the deformation process of I-beam will be given to analyze the impact response mechanics. The fracture morphologies of 3-D braided composite I-beam after impact test will be compared with those from FEA results.

\section{Experimental approach}

\subsection{3-D braided composite I-beam manufacture}

The 3-D braided I-shape preforms were manufactured by four-step braiding process. The array of fiber tows on the braiding machine bed is shown in Figure 1(a). The arrays for flanges and web were $14 \times 2$ and $2 \times 18$, separately. The braiding preforms with braiding angle of $30^{\circ}$ were made from T700-12K carbon fiber. The composite I-beams were manufactured by VARTM process. As is shown in Figure 1(b), the I-beam mold is composed of four parts to make it easy to assemble and separate. The I-beam preform was put inside the mold and covered with vacuum bag. One port for resin injection and one port connected to vacuum pump to remove air were set and their positions are shown in Figure 1(c). The vacuum pressure in the bag was about 0.1 MPa before resin injection. In order to decrease the porosity in composite, deaeration was conducted in a vacuum chamber before the epoxy resin was injected into the preform. The viscosity of the epoxy resin is about $1500 \mathrm{mpa} . \mathrm{s}$ at $25^{\circ} \mathrm{C}$. The impregnation process was completed under $40^{\circ} \mathrm{C}$ to assist more rapid flow of the resin. The filling speed was about $4 \mathrm{~mm} / \mathrm{s}$ during resin transfer under the vacuum pressure of $0.06 \mathrm{MPa}$. The curing condition included $90^{\circ} \mathrm{C}$ for 2 hours, $110^{\circ} \mathrm{C}$ for 1 hour and $130^{\circ} \mathrm{C}$ for 4 hours. As is shown in Figure 1(d), the 3-D braided composite I-beam was cut into the test length of $150 \mathrm{~mm}$. The length and the thickness of the flanges are $22 \mathrm{~mm}$ and $2 \mathrm{~mm}$, separately, which are the same as those of the web. The fiber volume fraction is $40 \%$.

\subsection{Transverse impact tests}

The transverse impact tests were conducted on a modified split Hopkinson pressure bar (SHPB). Figure 2 shows the test setup and test principle. The test system was composed of striker bar, incident bar and sample holder. When the striker bar 
impacted the incident bar, an elastic stress wave with twice the length of the striker bar was generated and spread in the incident bar. When the stress wave got the interface between the incident bar and the sample, one part of the wave went through the sample and the other part reflected back to the incident bar. When the reflected stress wave arrived at the other surface of the incident bar, it was reflected again to be another impact stress wave. This process repeated several times with decreasing the stress. The impact load $P$, displacement $\mu$ and energy absorption $W$ were calculated as followed,

$$
\begin{aligned}
& P(t)=E A\left[\varepsilon_{I}(t)+\varepsilon_{R}(t)\right] \\
& \mu(t)=C_{0} \int_{0}^{t}\left[\varepsilon_{I}(t)-\varepsilon_{R}(t)\right] \mathrm{d} t \\
& C_{0}=\sqrt{E / \rho} \\
& W=\int_{0}^{t} \frac{1}{2} P(t) \mu(t) \mathrm{d} t=\frac{1}{2} E A C_{0} \int_{0}^{t}\left[\varepsilon_{I}^{2}(t)-\varepsilon_{R}^{2}(t)\right] \mathrm{d} t
\end{aligned}
$$

where $E, A$ and $\rho$ are the modulus, cross section area and density of the bar, separately. $\varepsilon_{I}(t)$ and $\varepsilon_{R}(t)$ are the strain gauge signals of the incident and the reflect pulses. $C_{0}$ is the velocity of wave propagation in the incident bar.

Three different impact gas pressures (0.2 MPa, 0.4 MPa and 0.6 MPa ) were set to generate three different impact velocities $7 \mathrm{~m} / \mathrm{s}, 12 \mathrm{~m} / \mathrm{s}$ and $17 \mathrm{~m} / \mathrm{s}$. The span of the I-beam fixed by the holder was $100 \mathrm{~mm}$.

\section{Finite element analysis (FEA)}

\subsection{Material model}

The microstructure finite element analysis approach has been applied to characterize the mechanical properties of 3-D braided composites [16-18]. A microstructure model is composed of each component with different material properties which is benefit for obtaining the local response.

In this paper, a microstructure model of 3-D braided composite I-beam was established as shown in Figure 3. The model consisted of matrix and reinforcement. The matrix is epoxy resin which is isotropic material. The reinforcement was 
ented the four-step braiding process. The braiding yarns in the reinforcement were regarded as transversely isotropic unidirectional composites which included carbon fiber and epoxy resin. The mechanical properties of the braiding yarns were shown in Table1 which were calculated by unidirectional lamination theory. The matrix as isotropic material was assumed to obey the J2-isotropic hardening plastic theory. The yield properties of the braiding yarns were defined by using Hill's anisotropic plasticity model[19].

Ductile criterion and shear criterion were used to judge the damage initiation of 3-D braided composite I-beam under transverse impact[20]. For ductile criterion, the equivalent plastic strain is a function of the stress triaxiality [21]:

$\bar{\varepsilon}_{D}^{p l}\left(\eta, \dot{\bullet}^{p l}\right)=\frac{\varepsilon_{D}^{+} \sinh \left[k_{0}\left(\eta^{-}-\eta\right)\right]+\varepsilon_{D}^{-} \sinh \left[k_{0}\left(\eta-\eta^{+}\right)\right]}{\sinh \left[k_{0}\left(\eta^{-}-\eta^{+}\right)\right]}$

where $\varepsilon_{D}^{+}$and $\varepsilon_{D}^{-}$are the equivalent plastic strain at ductile damage initiation for uniaxial tensile and uniaxial compressive deformation, respectively. $\eta^{+}=1 / 3$ and $\eta^{+}=-1 / 3$ are the stress triaxiality in uniaxial tensile and uniaxial compressive deformation state. $k_{0}$ is a parameter.

For shear criterion, the equivalent plastic strain is a function of the shear stress ratio:

$$
\bar{\varepsilon}_{S}^{p l}\left(\tau_{S}, \dot{\bar{\varepsilon}}^{p l}\right)=\frac{\varepsilon_{S}^{+} \sinh \left[f_{S}\left(\tau_{S}-\tau_{S}^{-}\right)\right]+\varepsilon_{S}^{-} \sinh \left[f_{S}\left(\tau_{S}^{+}-\tau_{S}\right)\right]}{\sinh \left[f_{S}\left(\tau_{S}^{+}-\tau_{S}^{-}\right)\right]}
$$

where $\tau_{S}=\left(1-k_{S} \eta\right) / \phi$ with $\phi=\tau_{\max } / \sigma_{e q}$, and $\varepsilon_{S}^{+}$and $\varepsilon_{S}^{-}$correspond to the equivalent plastic strain at shear damage initiation for uniaxial tensile and compressive deformation, respectively. The parameters $\tau_{S}^{+}$and $\tau_{S}^{-}$correspond to the values of $\tau_{S}$ at $\eta=\eta^{+}$and $\eta=\eta^{-}$, respectively. $k_{S}$ and $f_{S}$ are parameters. The damage initiation criterion is met when the following condition is satisfied

$$
\omega_{D}=\int \frac{d \bar{\varepsilon}^{p l}}{\bar{\varepsilon}_{D}^{p l}\left(\eta, \dot{\bar{\varepsilon}}^{p l}\right)}=1
$$

where $\omega_{D}$ is a state variable that increases monotonically with plastic deformation. At 
each increment during the analysis, the increase in $\omega_{D}$ is computed as

$$
\Delta \omega_{D}=\frac{d \bar{\varepsilon}^{p l}}{\bar{\varepsilon}_{D}^{p l}\left(\eta, \dot{\bullet}^{p l}\right)} \geq 0
$$

The damage initiation criterion is met when the following condition is satisfied

$$
\omega_{S}=\int \frac{d \bar{\varepsilon}^{p l}}{\bar{\varepsilon}_{S}^{p l}\left(\tau_{S}, \dot{\bar{\varepsilon}}^{p l}\right)}=1
$$

where $\omega_{S}$ is a state variable that increases monotonically with plastic deformation. At each increment during the analysis, the increase in $\omega_{S}$ is computed as

$$
\Delta \omega_{S}=\frac{d \bar{\varepsilon}^{p l}}{\bar{\varepsilon}_{S}^{p l}\left(\tau_{S}, \dot{\bar{\varepsilon}}^{p l}\right)} \geq 0
$$

After damage initiation, the material stiffness was degraded gradually according to the specified damage evolution law. In this paper, the damage evolution law was based on the energy dissipated during the damage process. It assumes that the degradation of the stiffness associated with each active failure mechanism can be modeled using a scalar damage variable, $d_{i}\left(i \in N_{a c t}\right)$, where $N_{a c t}$ represents the set of active mechanisms.

$$
d_{i}=\frac{{\stackrel{\dot{\bar{\varepsilon}}^{p l}}{\bar{\varepsilon}}}_{\overline{u_{f}}}^{\bar{u}_{f}}}{{\stackrel{\dot{\bar{u}}_{f}^{p l}}{\bar{u}}}^{p l}}
$$

where the equivalent plastic displacement at failure is computed as $\bar{u}_{f}^{p l}=\frac{2 G_{f}}{\sigma_{y 0}}$ and $\sigma_{y 0}$ is the value of the yield stress at the time when the failure criterion is reached.

The fracture energy, $G_{f}$ can be specify.

At any given time during the analysis, the stress tensor is given by the scalar damage equation

$$
\sigma=(1-D) \bar{\sigma}
$$

where $D$ is the overall damage variable computed in terms of the individual damage 
variables, $d_{i} . \sigma$ is the effective (or undamaged) stress tensor computed in the current

increment. $\bar{\sigma}$ is the stresses that would exist in the material in the absence of damage.

\subsection{Transverse impact test model}

Figure 4 shows the transverse impact test model. The mesh schematic of the model is given in Figure 4(a). Eight-node element type C3D8R was set for the braiding yarns and the incident bar with relatively regular surfaces, while four-node element type C3D4 was chosen for the matrix which had complex surfaces inside. In order to make sure the parts share the same nodes between the interfaces, all parts were meshed together. The total number of the elements was about 2,700,000. Figure 4(b) shows the boundary condition of the model. Both the ends of the I-beam were fixed for displacement and rotation. A stress wave was set on the surface of the incident bar with the length of $1800 \mathrm{~mm}$ which had only displacement towards the impact direction. The surfaces between the braiding yarns and the matrix were tied together.

\section{Results and discussion}

\subsection{Mechanical responses}

The mechanical responses of 3-D braided composite I-beams under transverse impact loading were evaluated by load-time history, displacement-time history and total energy absorption. Figures 5(a)-(c) show the load-time histories of I-beams under three different impact gas pressures from experimental and FEM results. The curves were fluctuant and the peak load decreased during the four impact cycles. This was because that the stress wave was reflected several times in the incident bar with impact energy dissipation. The result from FEM shows a good agreement with that from experiment. Figure 5(d) compares the peak loads under different impact gas pressures. The impact load increased with the increase in impact gas pressure. Figure 6(a) illustrates the displacement-time history. The displacement increased when the stress wave impacted the sample and it became constant when the stress wave spread in the incident bar. Both the displacement and the total energy absorption shown in Figure 6(b) increased with the increase in impact gas pressure.

\subsection{Damage evolution and stress distribution}




\subsubsection{Damage evolution}

Figure 7 illustrates the damage evolution of 3-D braided composite I-beam under transverse impact gas pressure 0.6MPa.As is shown in Figure 7(a), eight time points (a-h) were chosen. Figure 7(b) and (c) show the damage evolution of matrix and reinforcement. When the incident bar impacted the I-beam, the stress wave spread from the top flange to the web. In the beginning (a-d), the spread of the stress along the impact direction in the matrix was faster than that in the reinforcement. And the stress in the reinforcement propagated slanting forward to the web. This is due to the complex braiding structure in the reinforcement, which will be explained in the next section. There was a little deformation under the first impact cycle point 'e'. At the second impact cycle point ' $\mathrm{f}$ ', the connected part between top flange and web was broken. At the third impact cycle point ' $\mathrm{g}$ ', the top flange was fractured perpendicular to braiding direction. At the last impact cycle point ' $\mathrm{h}$ ', the fracture became severer and the stress decreased to a low level.

\subsubsection{Stress distribution}

In order to research the effects of the complex 3-D braided structure on the stress propagation in the composite I-beam, three paths were chosen in the braided preform. As is shown in Figure 8(b), path1 was in the middle of the top flange along the braiding direction. During the first impact cycle1 from time-point ' $a$ '-' $d$ ', the stress distribution was mainly focused on the impact point and the two fixed edges. When the stress wave arrived at the fixed edges, it was reflected and the tensile stress doubled. From the first impact cycle point 'e' to the forth impact cycle point ' $h$ ', the impact damaged area enlarged gradually.

As is shown in Figure 8(c), path2 went from top flange to the bottom flange along the impact direction in the cut view A-A shown in Figure 8(a). The stress level in both the top flange and the bottom flange was high. This is because the top flange was under compression and the bottom flange was under tension.

Figure 8 (d) illustrates the path3 in the view cut section B-B shown in Figure 8(a). The path traveled obliquely in the web. The stress distribution along path3 evolved gradually to a ' $M$ ' shape. As it was talked in the last section, the stress in the 
reinforcement propagated slanting forward to the web shown in Figure 7(c). The stress level in both sides of the web was higher than that in the middle along the impact direction. This is due to the geometric distribution of the braiding yarns in the reinforcement. Figure 9 shows the tensile and compressive stress distributions in braiding yarns with different orientation. Two braiding yarns in the web were used as an example. When the stress $F$ was loaded on a yarn, the part above the loading area was imposed by tensile stress but the other part below the loading area carried the compressive stress. The middle area along the loading direction was balanced out by the tensile stress and compressive stress.

\subsection{Fracture morphology}

Figures 10(a)-(c) illustrate the fracture morphologies of 3-D braided composite I-beam after transverse impact tests from experimental and FEM results. The whole beam showed a slight bending towards the impact direction. The impact damage was mainly focused on the junction between the top flange and the web. The damage of I beam increased with the increase in impact gas pressure. At the impact gas pressure of $0.2 \mathrm{MPa}$, the matrix crack propagated around the edges of the braiding yarns on the top flange and a crack was generated along the impact direction on the web. When the impact gas pressure increased to $0.4 \mathrm{MPa}$ and $0.6 \mathrm{MPa}$, local indentation on the top flange was clear. There were more serious matrix crack and fiber breakage on the top flange above the web. From the side view in Figure 10(b) and (c), the matrix crack on the web expanded to the outsides of the impact area. The FEM result showed good agreement with that from experiment which validate the established model.

\section{Conclusions}

The transverse impact responses of 3-D braided composite I-beam were studied in this paper. The impact tests were conducted by a modified SHPB under three different impact gas pressures. A microstructure geometric model was established for the finite element analysis. The result from the numerical method showed a good agreement with that from the experiment which validated the established model. The load, displacement and energy absorption increased with the increase in impact gas 


\section{References}

1. K. B, Three-dimensional braiding for composites: A review. Textile Research Journal, 2012. 83(13): p. 1414-1436.

2. Hamada $\mathrm{H}$, et al., The crushing performance of a braided I-beam. Composites Science and Technology, 1999. 59(12): p. 1881-1890.

3. Ss Y, Tw C, and Fk K, Flexural and axial compressive failures of three-dimensionally braided composite I-beams. Composites, 1986. 17(3): p. 227-232.

4. Barbero E J, Lopez-Anido R, and Davalos J F, On the Mechanics of Thin-Walled Laminated Composite Beams. Journal of Composite Materials, 1993. 27(8): p. 806-829.

5. J S P, Bn P, and E H I, The Clear Creek Hybrid Composite I-Girder Pedestrian Bridge. Journal of Composites for Construction, 1999. 3: p. 4.

6. Shin D K, Kim N-I, and Kim M-Y, Exact stiffness matrix of mono-symmetric composite I-beams with arbitrary lamination. Composite Structures, 2007. 79(4): p. 467-480.

7. Hai N D, et al., Structural behavior of hybrid FRP composite I-beam. Construction and Building Materials, 2010. 24(6): p. 956-969.

8. He Z, et al., Failure behavior of 2D C/SiC I-beam under bending load. Composite Structures, 2015. 132: p. 321-330.

9. Kim N-I and Lee J, Lateral buckling of shear deformable laminated composite I-beams using the finite element method. International Journal of Mechanical Sciences, 2013. 68: p. 
246-257.

10. Ayou $\mathrm{H}$, et al., Dynamic properties of 3-D orthogonal woven composite T-beam under transverse impact. Composites: Part A, 2008. 39: p. 1073-1082.

11. Zhang $M$, et al., Dynamic Behavior of 3D Biaxial Spacer Weft-Knitted Composite T-Beam Under Transverse Impact. Mechanics of Advanced Materials \& Structures, 2009. 16(5): p. 356-370.

12. Lihua $L$ and Bohong $G$, Transverse impact damage and energy absorption of three-dimensional orthogonal hybrid woven composite: experimental and FEM simulation. Journal of Composite Materials, 2008. 42(17): p. 1763-1786.

13. Baozhong $\mathrm{S}$, Dongmei $\mathrm{H}$, and Bohong $\mathrm{G}$, Transverse impact damage and energy absorption of 3-D multi-structured knitted composite. Composites Part B: Engineering, 2009. 40(6): p. 572-583.

14. Yan Z, et al., Transverse impact behaviors of four-step 3-D rectangular braided composites from unit-cell approach. Journal of Reinforced Plastics and Composites, 2012. 31(4): p. 233-246.

15. Shi $\mathrm{Y}$, et al., An experimental investigation on the low-velocity impact behavior of 3D five-directional braided composites. Polymers for Advanced Technologies, 2014. 25(12): p. 1386-1390.

16. Diansen $L$, et al., Finite element modeling of mechanical properties of 3D five-directional rectangular braided composites. Composites Part B: Engineering, 2011. 42(6): p. 1373-1385.

17. Bohong G, A microstructure model for finite-element simulation of 3D rectangular braided composite under ballistic penetration. Philosophical Magazine, 2007. 87(30): p. 4643-4669.

18. Zhang D, et al., Transverse tensile damage behaviors of three-dimensional five-directional braided composites by meso-scale finite element approach. Journal of Reinforced Plastics and Composites, 2015. 34(15): p. 1202-1220.

19. Wan $\mathrm{Y}, \mathrm{Wang} \mathrm{Y}$, and Gu B, Finite element prediction of the impact compressive properties of three-dimensional braided composites using multi-scale model. Composite Structures, 2015. 128: p. 381-394.

20. Simulia D, ABAQUS 6.12 theory manual. Providence, RI, USA: DS SIMULIA Corp, 2012.

21. Hooputra $\mathrm{H}$, et al., A comprehensive failure model for crashworthiness simulation of aluminium extrusions. International Journal of Crashworthiness, 2004. 9(5): p. 449-463. 
Table 1 The mechanical properties of braiding yarns and epoxy resin

\begin{tabular}{cccccccc}
\hline & $\begin{array}{c}\mathrm{E}_{11} \\
(\mathrm{GPa})\end{array}$ & $\begin{array}{c}\mathrm{E}_{22}=\mathrm{E}_{33} \\
(\mathrm{GPa})\end{array}$ & $\begin{array}{c}\mathrm{G}_{12}=\mathrm{G}_{13} \\
(\mathrm{GPa})\end{array}$ & $\begin{array}{c}\mathrm{G}_{23} \\
(\mathrm{GPa})\end{array}$ & $v_{12}=v_{13}$ & $v_{23}$ & $\begin{array}{c}\rho \\
\left(\mathrm{g} / \mathrm{cm}^{3}\right)\end{array}$ \\
\hline Braiding yarn & 161.72 & 7.82 & 3.62 & 2.85 & 0.25 & 0.32 & 1.60 \\
Epoxy resin & 2.4 & - & 0.89 & - & 0.35 & - & 1.13 \\
\hline
\end{tabular}

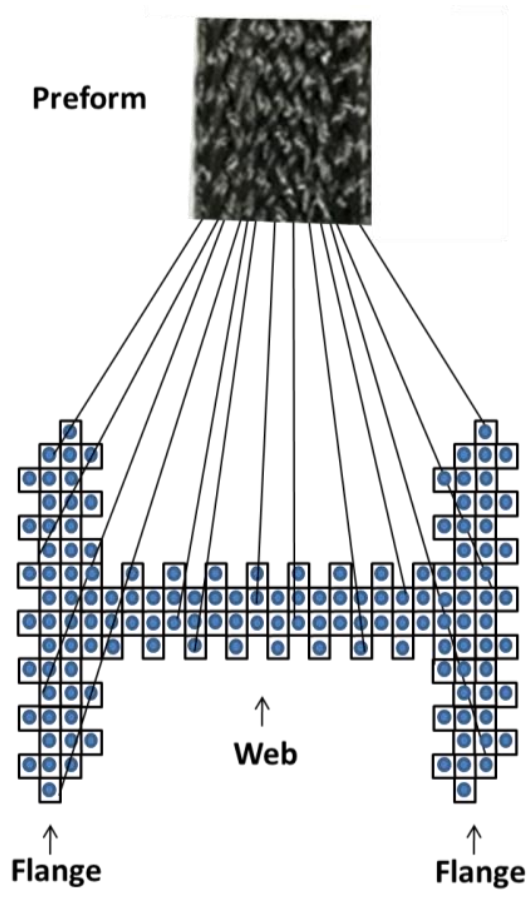

(a)
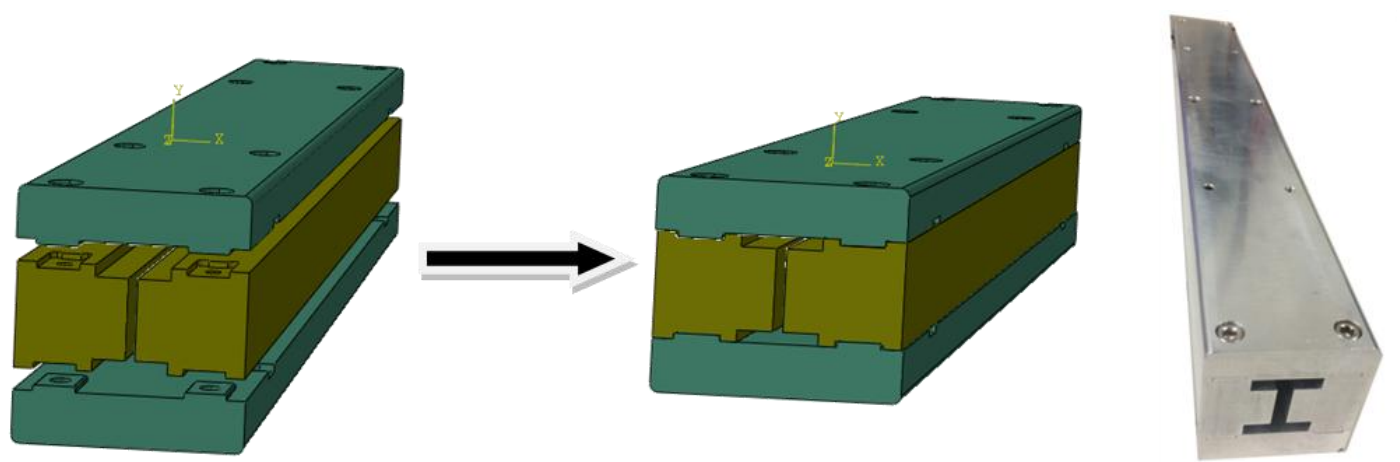

(b) 


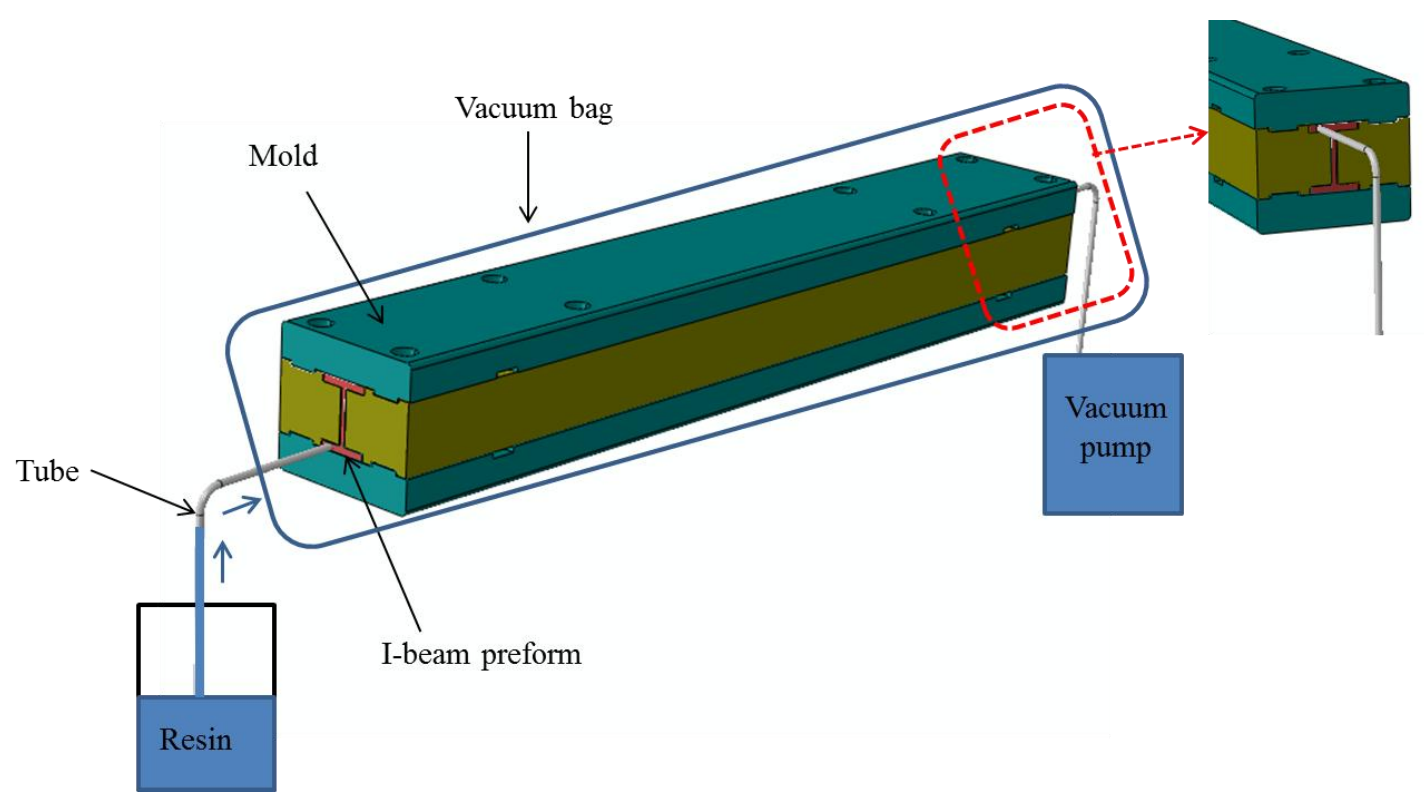

(c)

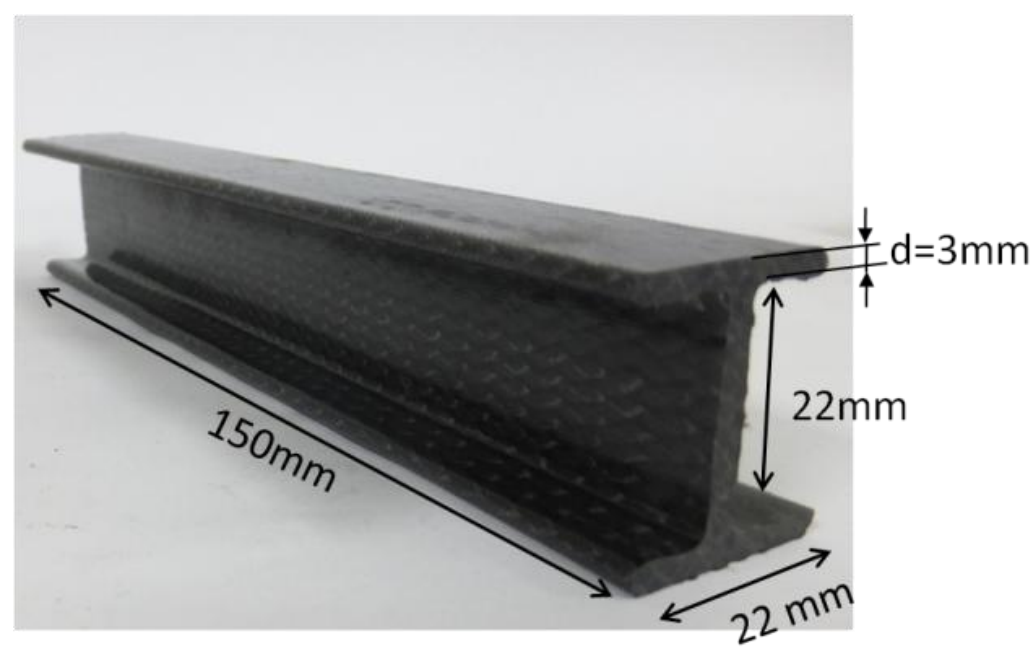

(d)

Figure1 (a) The array of fiber tows on the braiding machine;

(b)Design of the I-beam mold

(c) VARTM process

(d) 3-D braided composite I-beam 


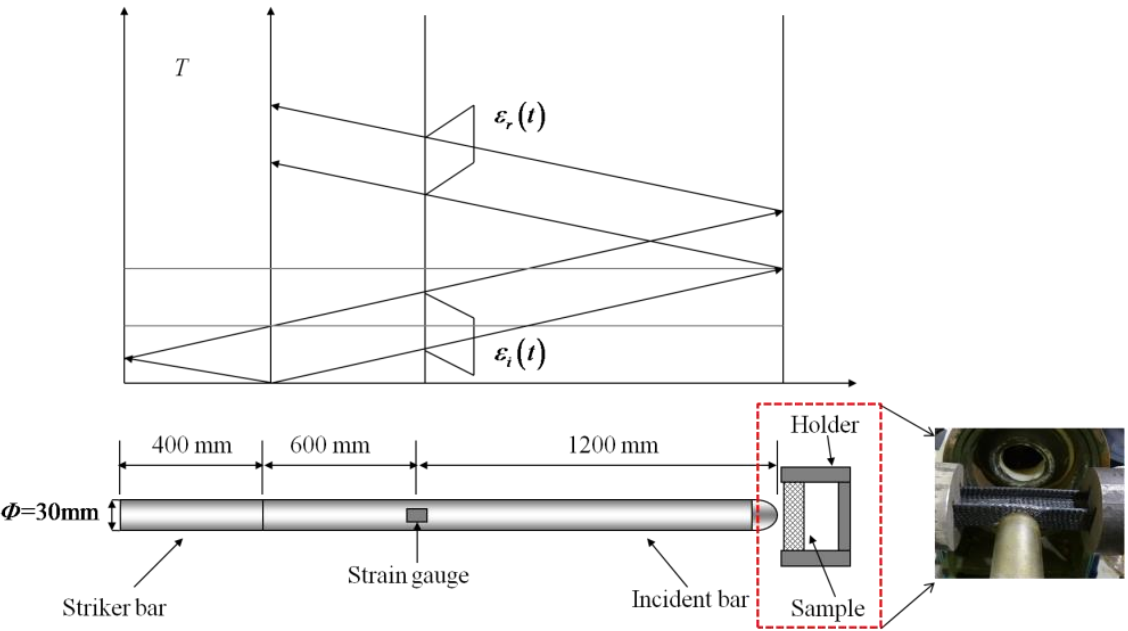

Figure 2 The transverse impact principle

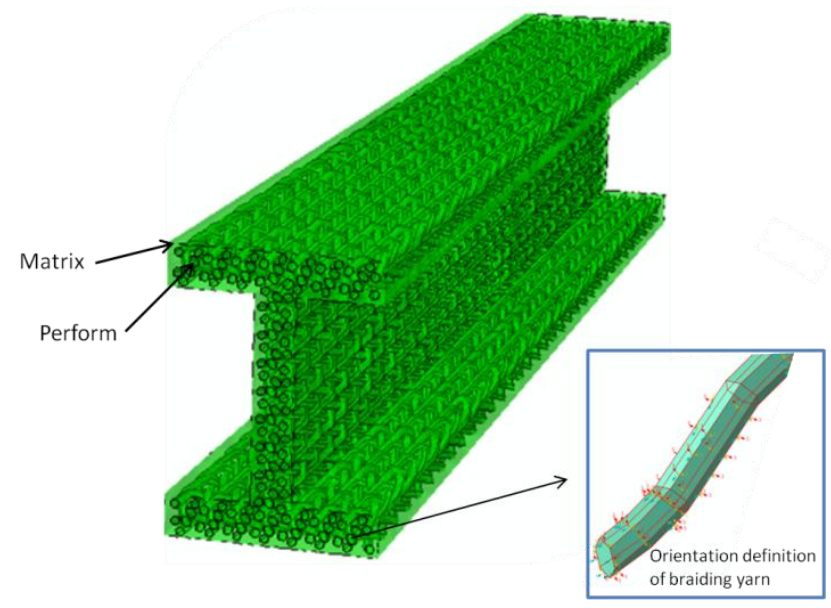

Figure 3 The microstructure model of 3-D braided composite I-beam

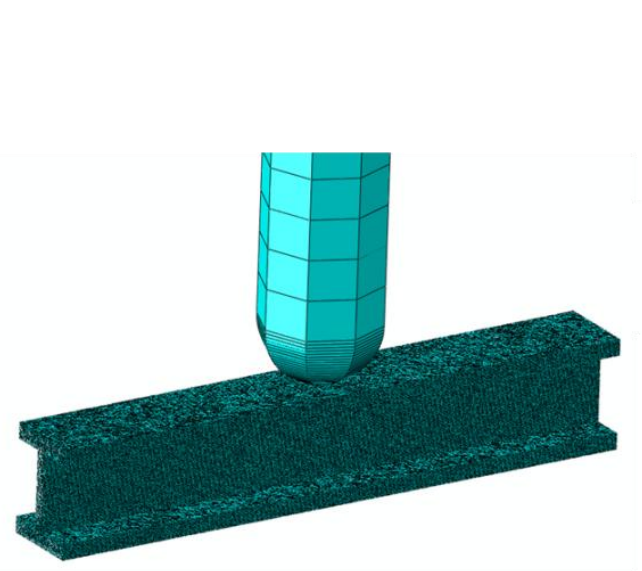

(a)

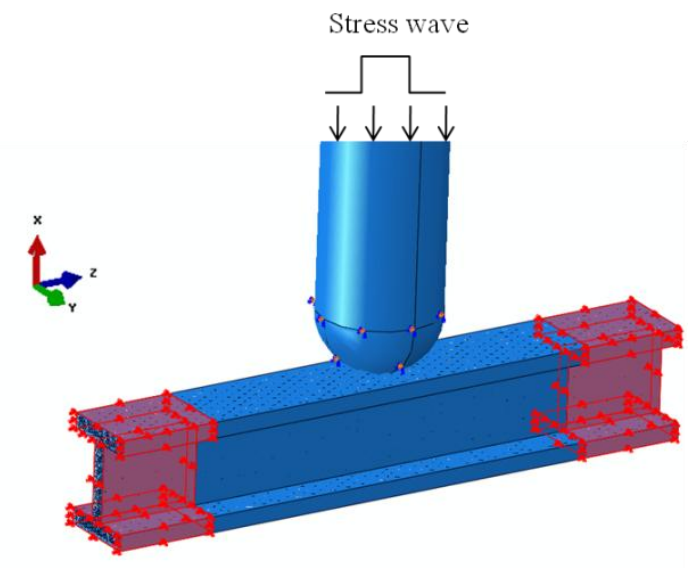

(b)

Figure 4 (a) Mesh schematic and (b) boundary condition of transverse impact test model 


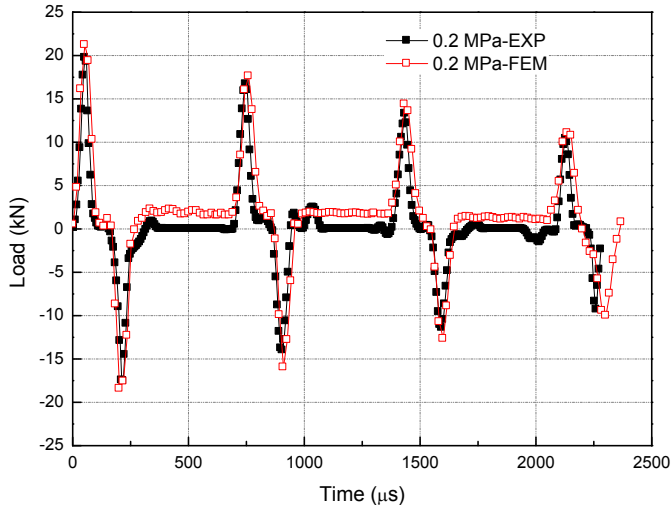

(a)

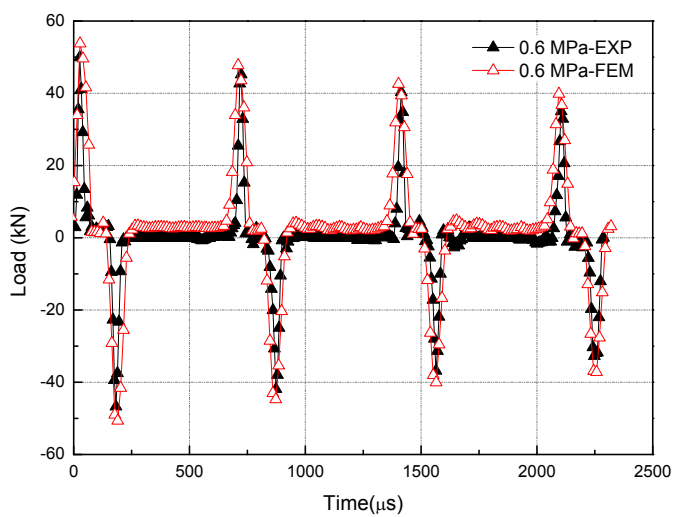

(c)

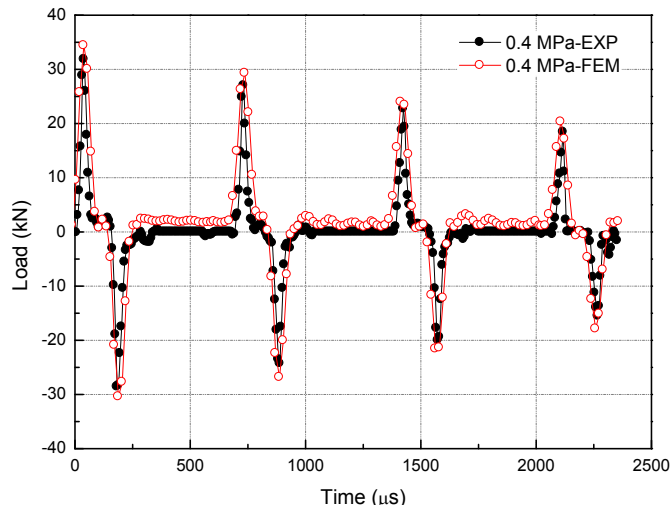

(b)

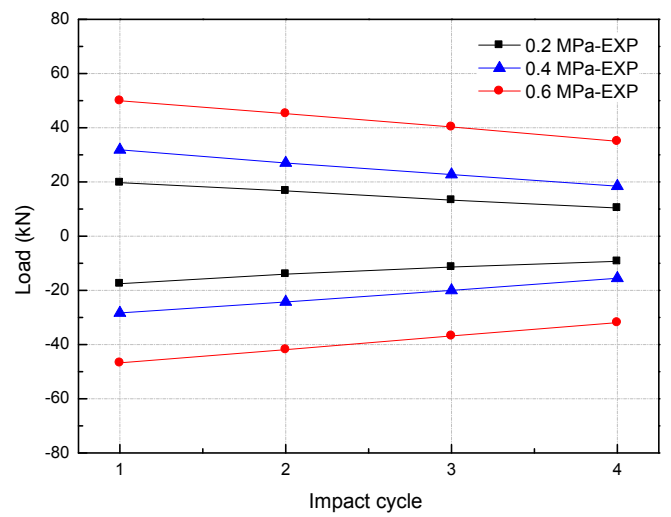

(d)

Figure 5 Load-time curves of 3-D braided composite I-beam under three impact gas pressures: (a) $0.2 \mathrm{MPa}$, (b) $0.4 \mathrm{MPa}$, (c) $0.6 \mathrm{MPa}$ and (d) the comparison of their peak loads

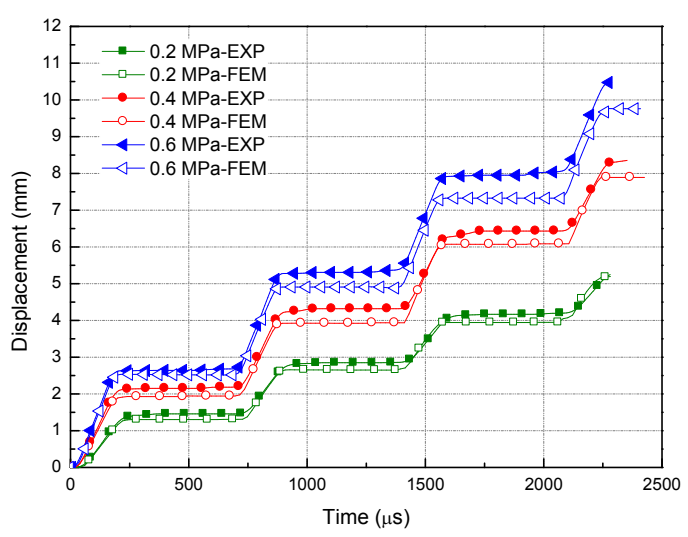

(a)

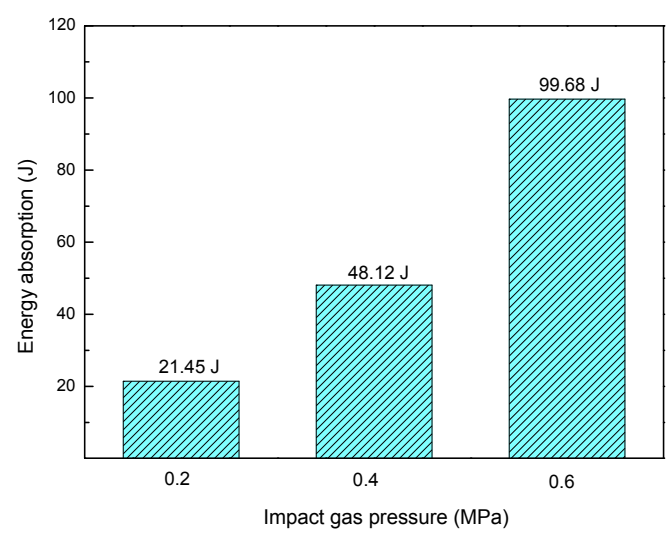

(b)

Figure 6 (a) Displacement-time curves; (b) Total energy absorption 


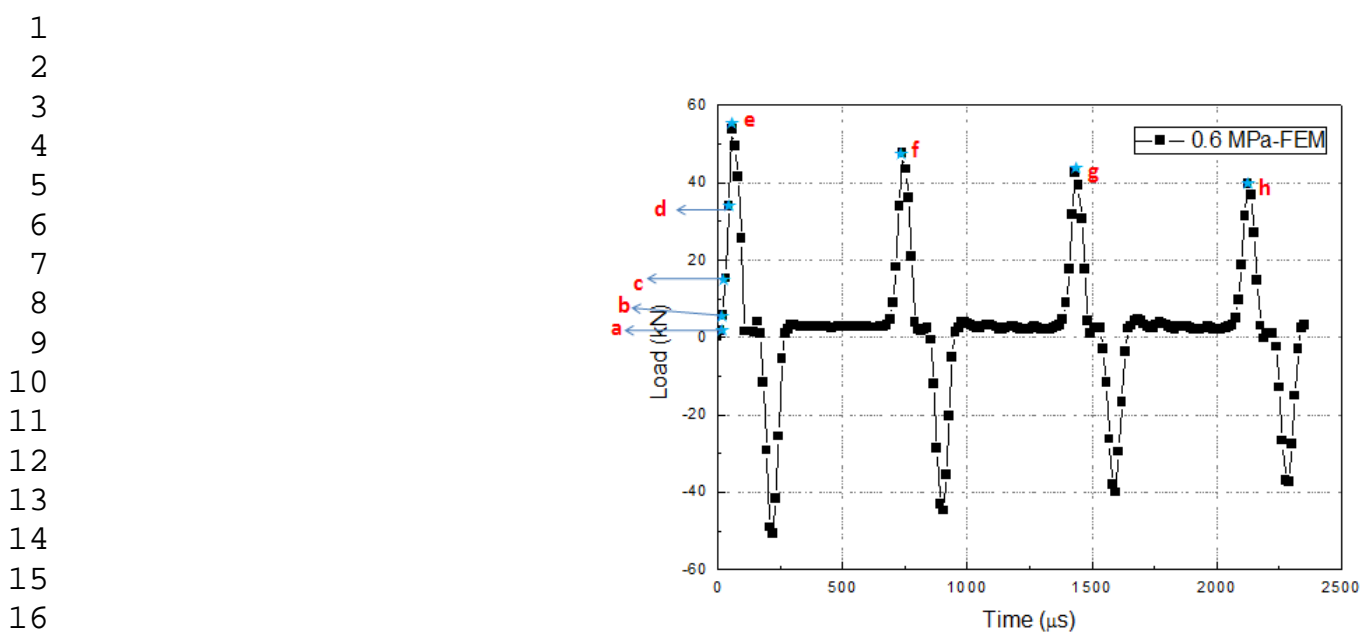

(a)

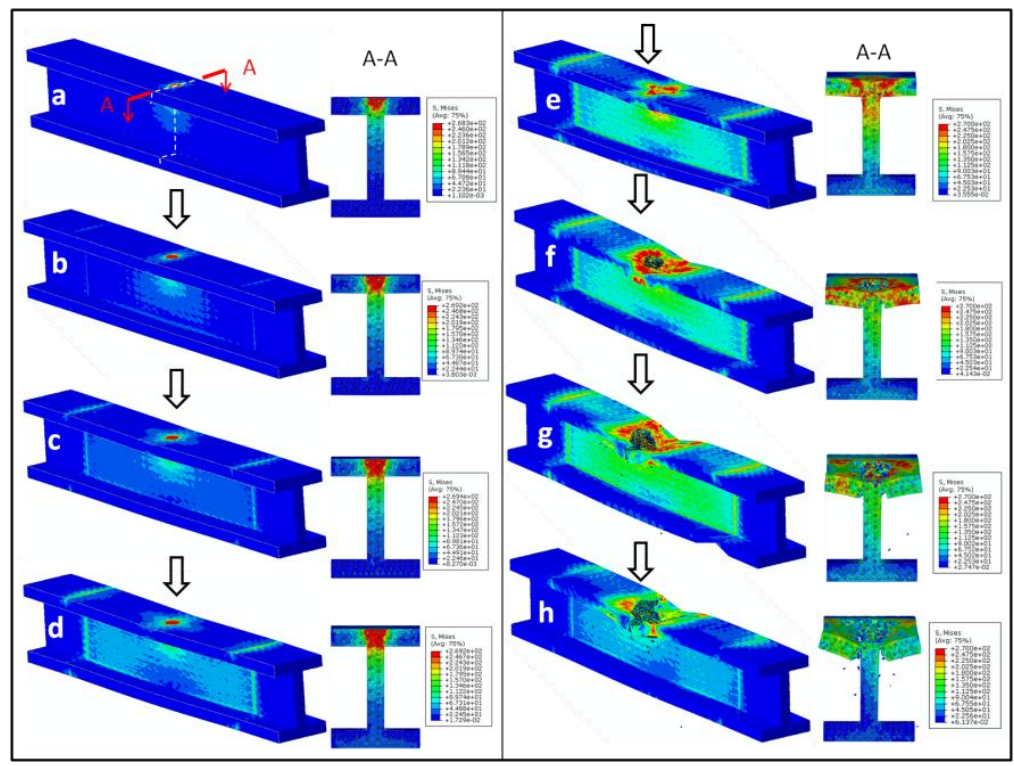

(b)

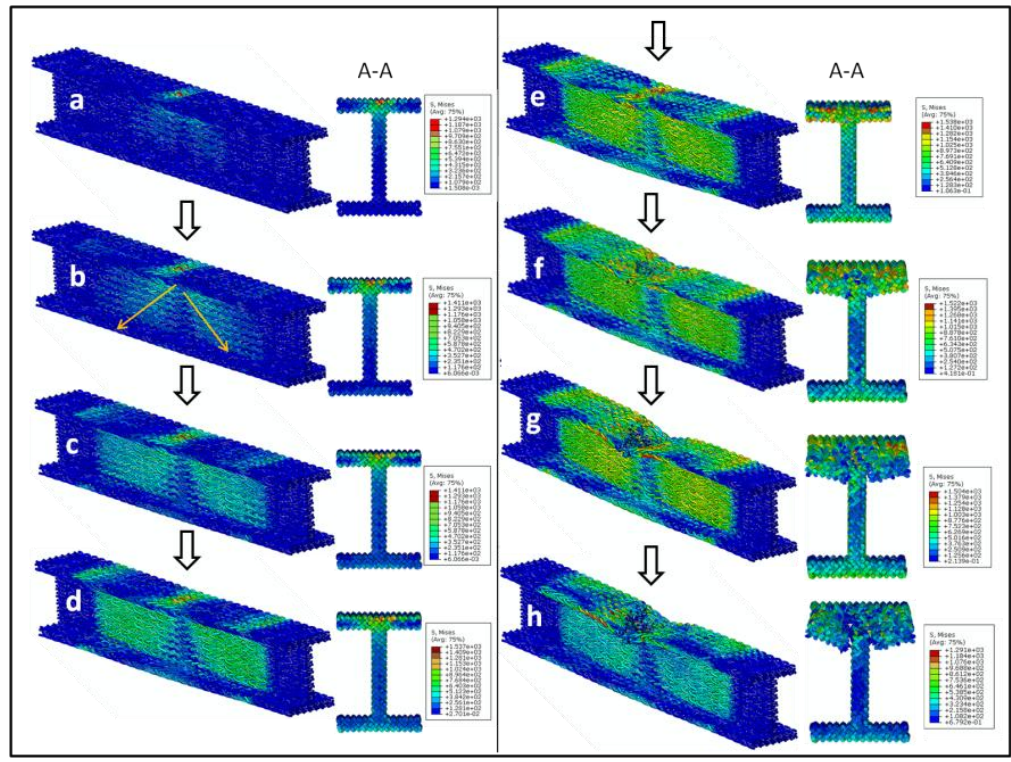

(c) 
Figure 7 (a) Eight time points chosen in the load-time curve.

Damage evolution of (b)matrix and (c)reinforcement
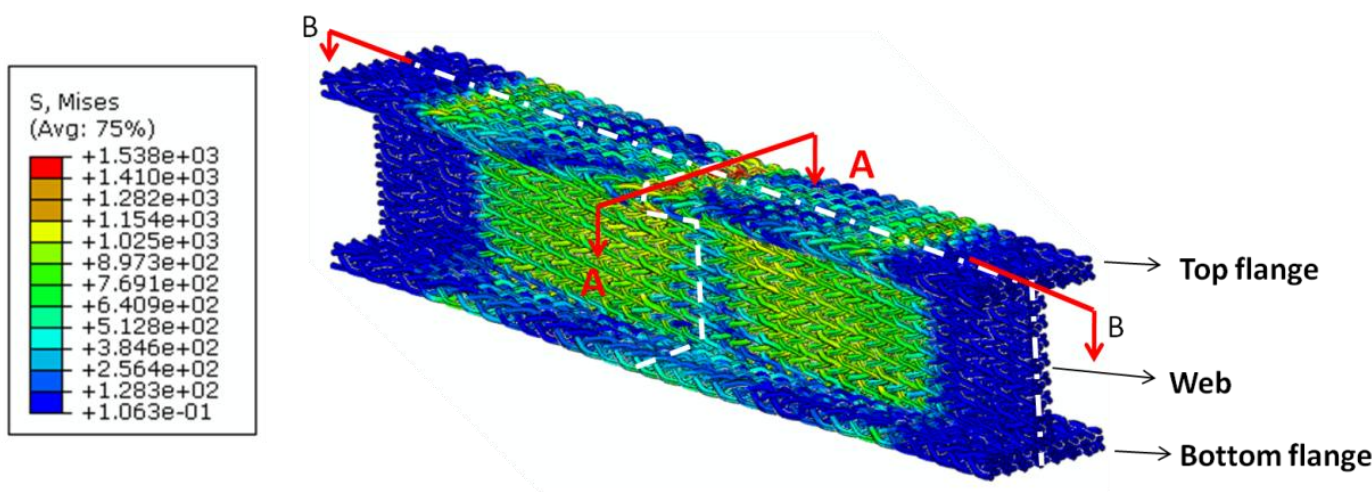

(a)

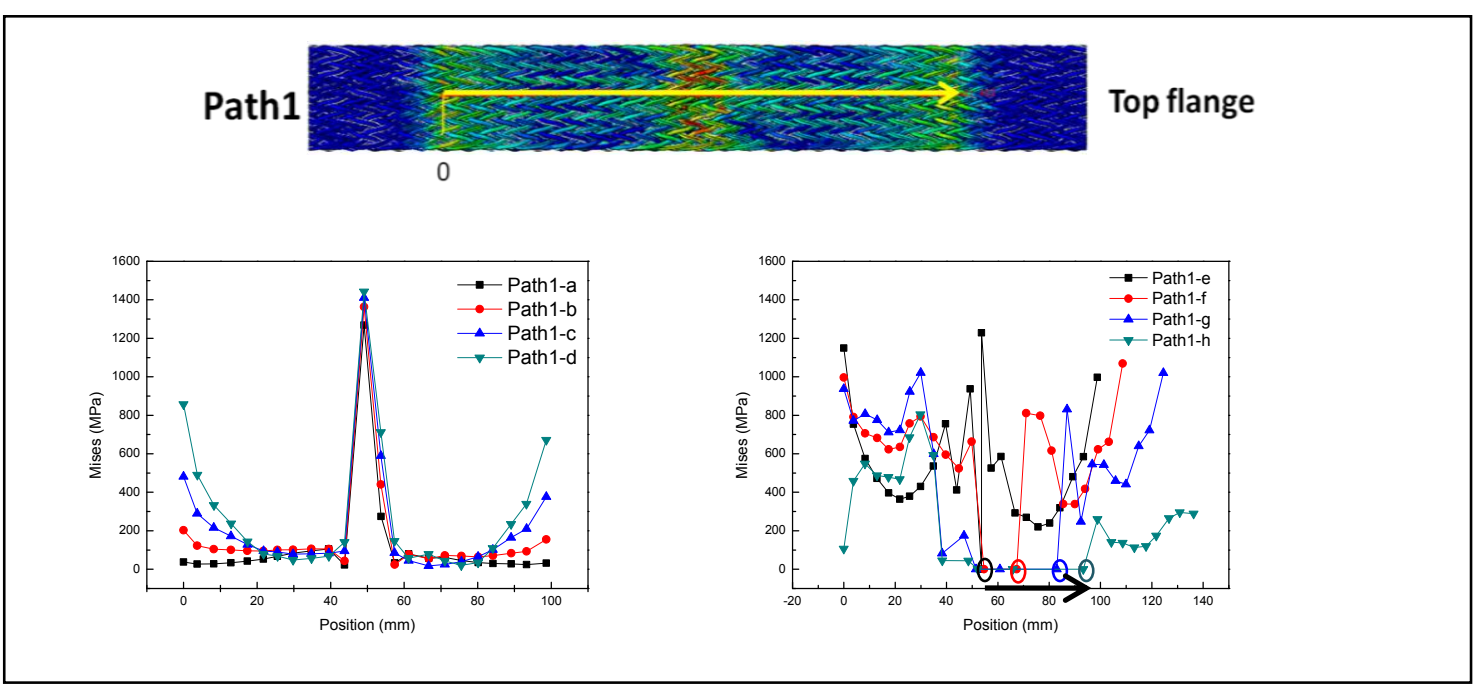

(b)

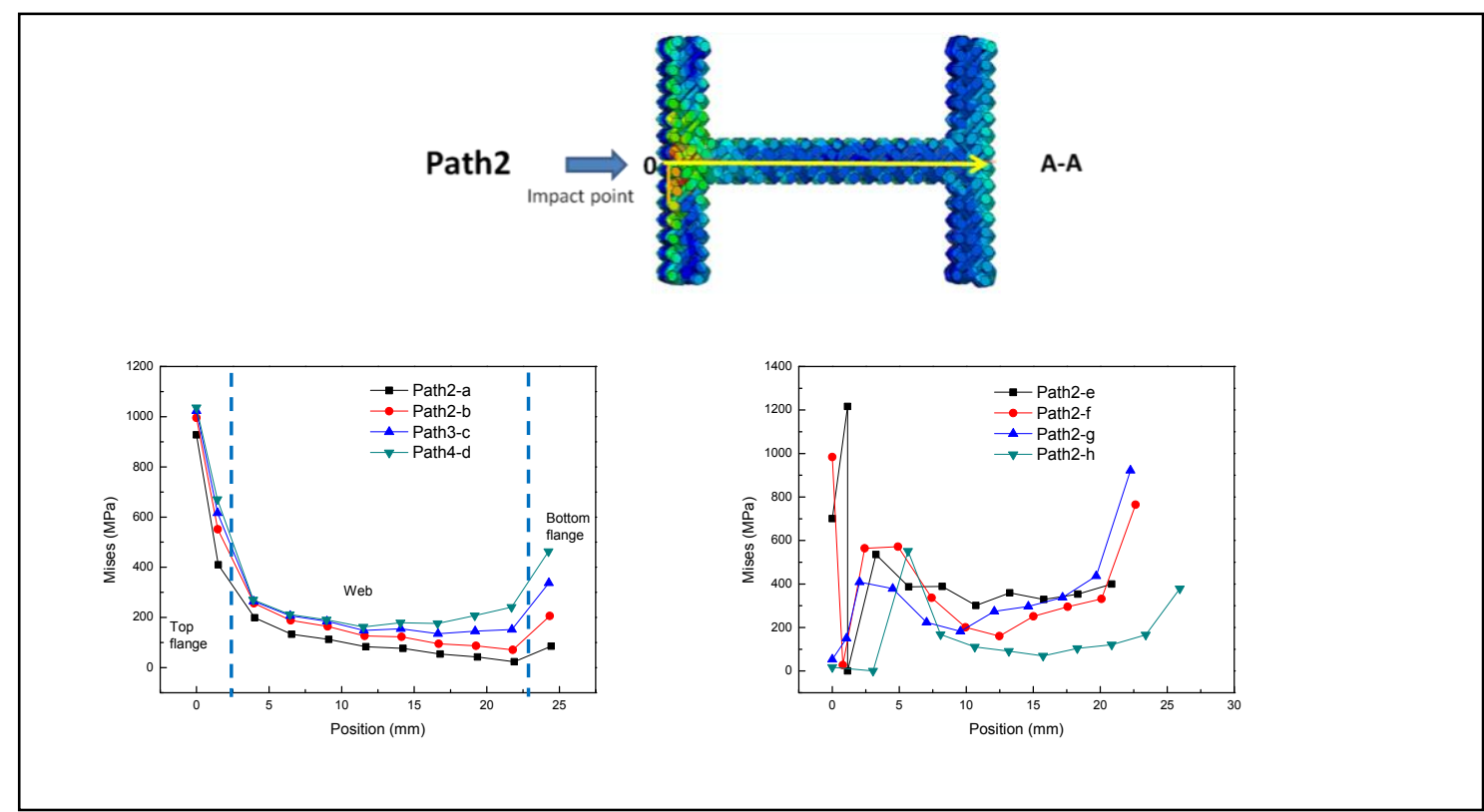

(c) 


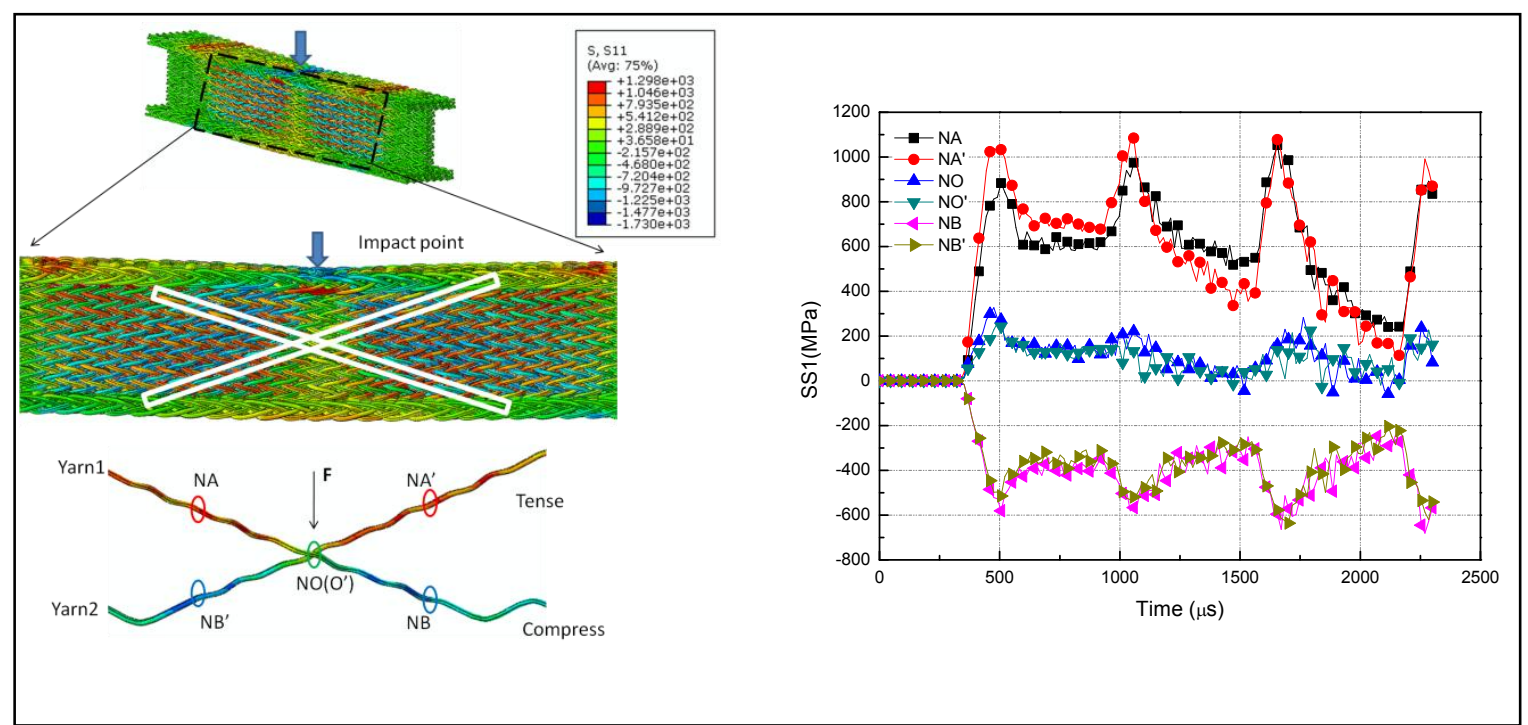

Figure 9 Tensile and compress stress distribution in the I-beam reinforcement

Figure 8 (a) Global view of 3-D braided I-beam reinforcement

The evolution of stress distribution in (b) path 1, (c) path 2 and (d) path 3 


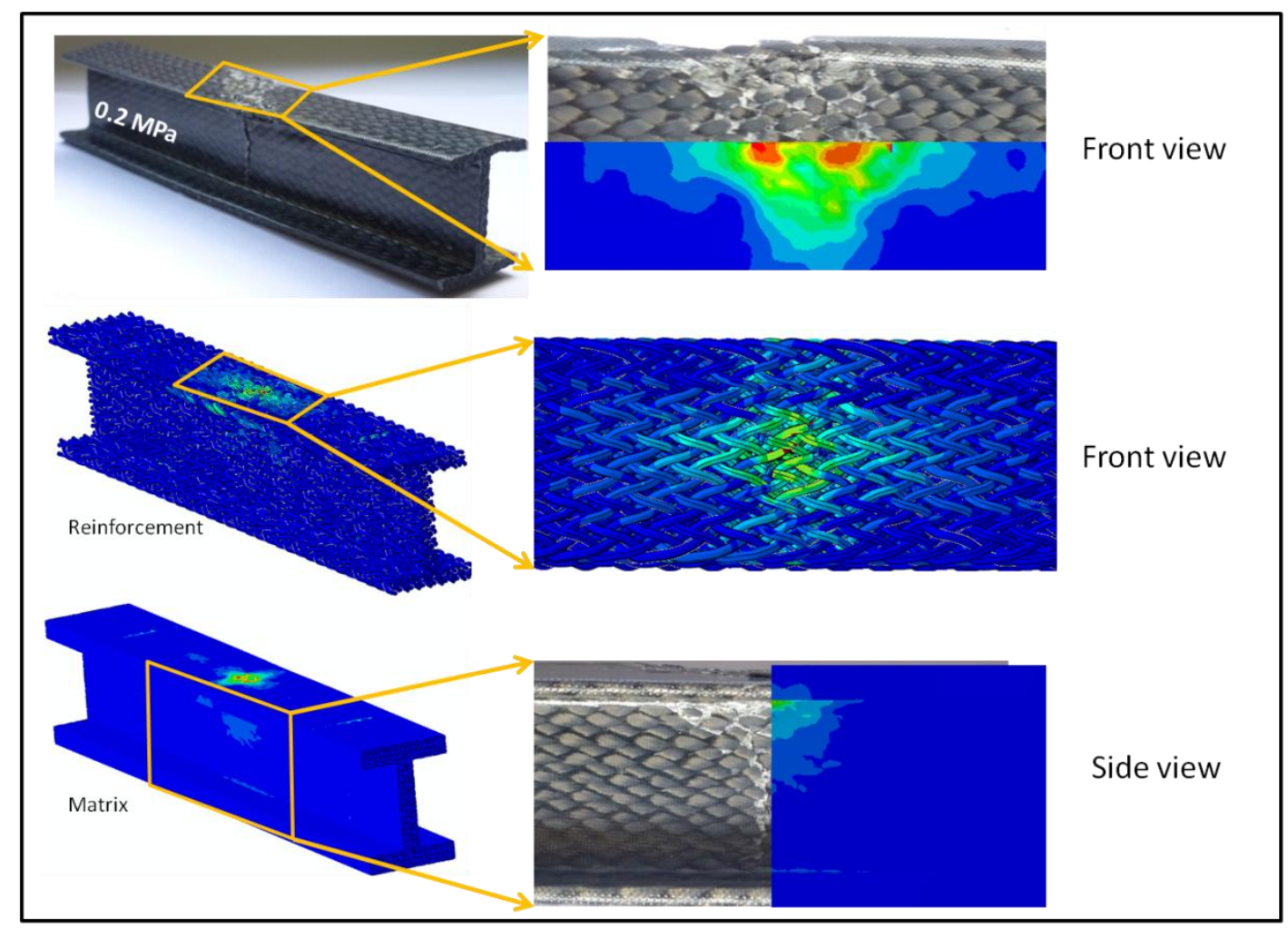

(a)

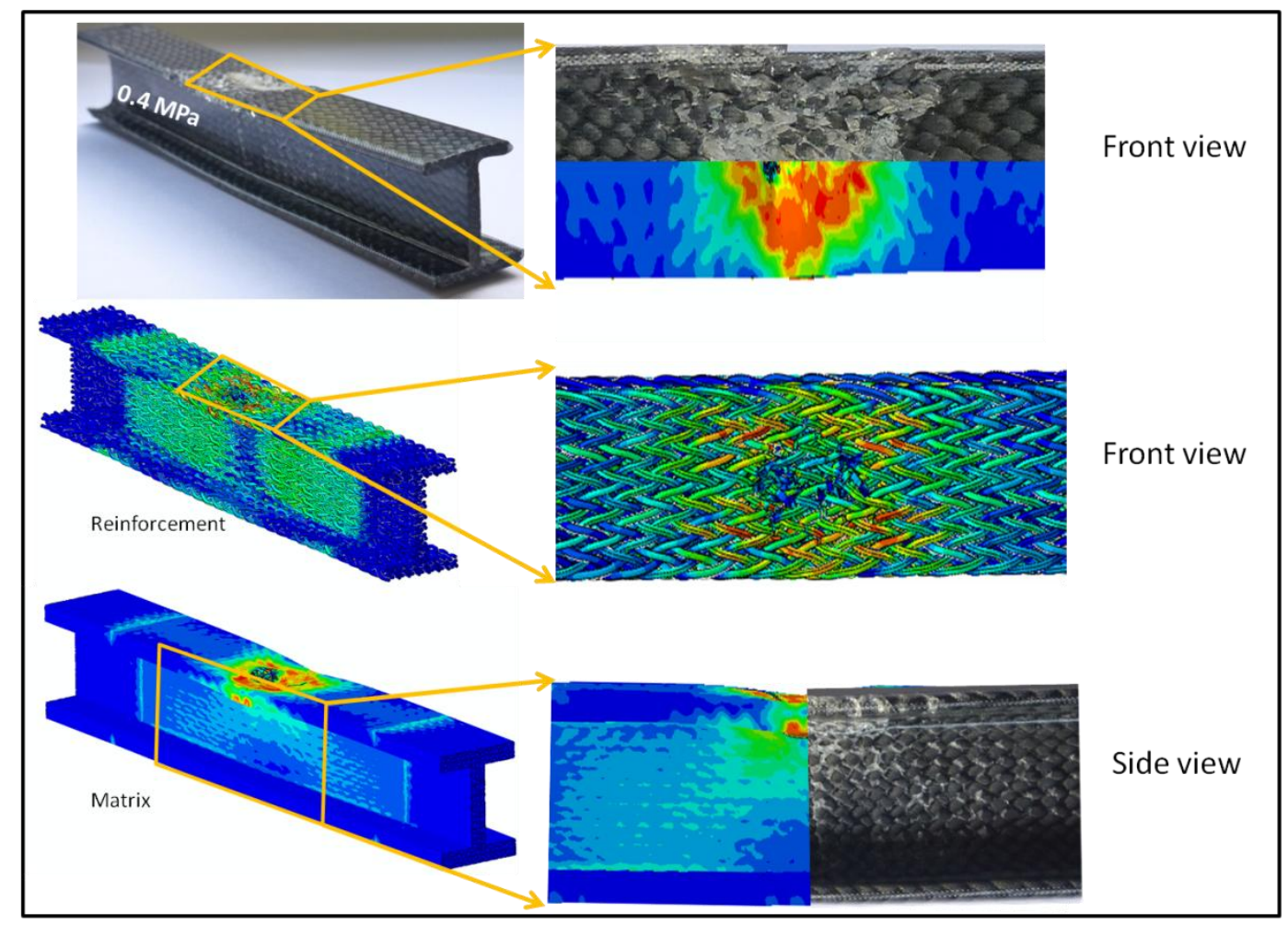

(b) 


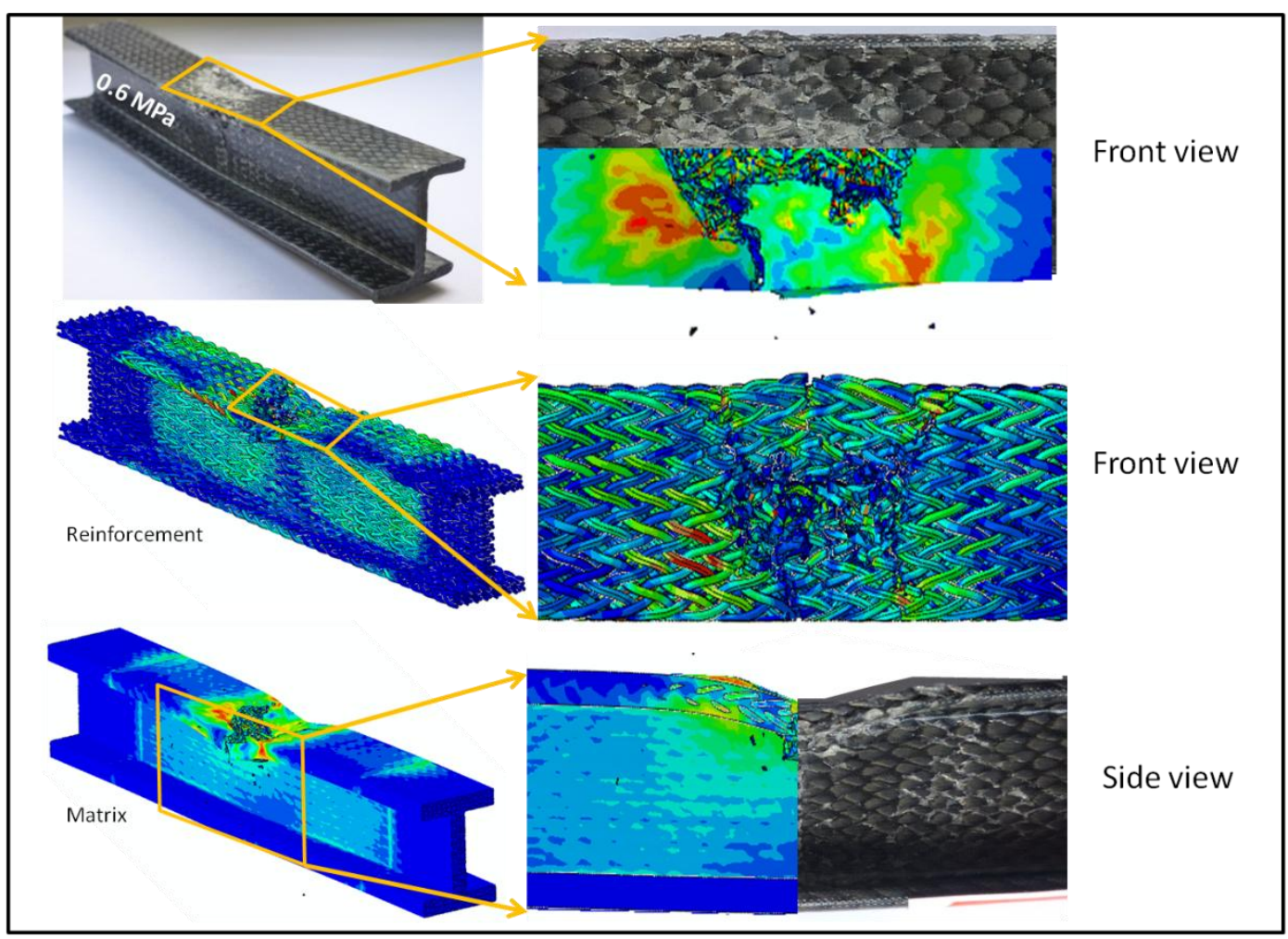

(c)

Fig. 10 The fracture morphologies of 3-D braided composite I-beam under impact gas pressure (a) $0.2 \mathrm{MPa}$, (b) $0.4 \mathrm{MPa}$ and (c) 0.6 MPa. 